\title{
Role of low dose Magnesium sulphate in eclampsia
}

\author{
Kajal Sinha*, Shail K. Sinha \\ Department of Obstetrics and Gynecology, Darbhanga Medical College and Hospital, Laheriasarai, Bihar, India
}

Received: 24 November 2018

Accepted: 07 January 2019

\section{*Correspondence:}

Dr. Kajal Sinha,

E-mail: amitkajal30@gmail.com

Copyright: $\odot$ the author(s), publisher and licensee Medip Academy. This is an open-access article distributed under the terms of the Creative Commons Attribution Non-Commercial License, which permits unrestricted non-commercial use, distribution, and reproduction in any medium, provided the original work is properly cited.

\section{ABSTRACT}

Background: Eclampsia is one of the challenging medical complications seen during pregnancy. With the use of magnesium sulphate for control of convulsion in eclampsia, it can be managed effectively.

Methods: This is a prospective study done in a tertiary care hospital. Considering low body mass index of patients of developing area, authors had used low dose regime of magnesium sulphate. 100 patients had been enrolled for low dose magnesium sulphate regime after categorizing patients as per inclusion and exclusion criteria. The primary outcome to be measured was recurrence of fits in any patients who received low dose magnesium sulphate. The secondary outcome measured were development of any toxicity, level of serum magnesium level, maternal and perinatal outcome.

Results: It was observed that $93 \%$ of the patients responded to low dose regime. $7 \%$ developed recurrence of fits for that additional dose of 2 gram of $20 \%$ magnesium sulphate was given to the patients. Not even a single patient developed signs of toxicity. $94 \%$ and $95 \%$ of the patients acquired therapeutic level of serum magnesium at 4 hours and 10 hours of magnesium sulphate administration, respectively. Maternal mortality was $5 \%$ and perinatal mortality was $24.4 \%$.

Conclusions: Low dose of magnesium sulphate can prevent and treat eclampsia. Low dose regimen also reduces incidence of toxicity with improved maternal and perinatal outcome.

Keywords: Eclampsia, Magnesium sulphate, Maternal mortality, Perinatal outcome

\section{INTRODUCTION}

Eclampsia is a Greek word meaning 'bolt from the blue'. Eclampsia is a disorder with complex pathogenesis affecting all the organ systems of the body. Among various anticonvulsants, magnesium sulphate $\left(\mathrm{MgSO}_{4}\right)$ is considered drug of choice for controlling convulsion and improving other secondary outcomes. ${ }^{1}$ The basic principles of management of eclampsia are control of convulsion, control of blood pressure, prompt steps to conduct delivery and general nursing care. The use of anticonvulsant varies in different parts of the world. Magnesium sulphate was foremost recommended and used in 1906 and has been popular for over 68 years in
USA. Dr. J. A. Pritchard used magnesium sulphate as anticonvulsant in eclampsia cases at Parkland Hospital, USA. Magnesium sulphate acts on peripheral myo-neural junction and blocks the impulse transmission. There are different magnesium sulphate dose regimes which have been used to treat eclamptic fits. ${ }^{2}$ Pritchard regime is most commonly used among all anticonvulsant regimes. Flower et al did dose titration and modified dose of magnesium sulphate according to body weight and serum level of magnesium sulphate of eclamptic women. ${ }^{3,4}$ Women of developing countries are generally lean and thin. Later on, it was suggested that dose of magnesium sulphate should be low in light weight women. Sardesai Suman et al used low dose of magnesium sulphate in 
Indian women and found it to be very effective and safe in controlling convulsion. This safety aspect is important in low resource settings where laboratory testing of serum magnesium is not available. The aim of the present study was to evaluate the effectiveness of low dose magnesium sulphate by analysing recurrence of fits, to assess the magnesium related toxicity and maternal and perinatal outcome. $^{5}$

\section{METHODS}

This was a prospective study carried out over a period of one year in the department of Obstetrics and Gynecology at tertiary care hospital in a developing country. 198 cases of eclampsia got admission in labour room, but 98 cases were excluded because of exclusion criteria. 100 cases of eclampsia were randomly selected from labour room for inclusion in the study. Cases who received anticonvulsant treatment before getting admission to the hospital and those who presented with complications like cerebrovascular accident, renal failure, aspiration pneumonitis, pulmonary edema and HELLP syndrome were excluded from the study. Standard principles of management of eclampsia were followed i.e. maintenance of airway, breathing and circulation, use of anticonvulsant, antihypertensive and general care of the patient. Following protocol was used in low dose magnesium sulphate regime in eclampsia.

Written informed consent was taken from the patient relatives who were included in the study. Loading dose of four grams of magnesium sulphate (20\% solution) was given intravenous slowly over 5-10 minutes time and 3 grams of magnesium sulphate $(50 \%)$ was given deep intramuscular in both buttocks simultaneously. Subsequently, maintenance dose of magnesium sulphate 2.5 grams (50\% solution) was given deep intramuscularly in alternate buttock every four hour till 24 hours after delivery or after last fit, whichever was later. If there was recurrence of convulsion after initial loading dose, additional 2 grams of $20 \%$ magnesium sulphate solution was given intravenously. If fits were not controlled after giving such two additional doses, then the case was shifted to standard Pritchard regime and was labelled as failure of low dose regime.

Before starting anticonvulsant therapy, blood sample was taken for baseline serum magnesium level, then at 4 hours and 10 hours. Efficacy of low dose magnesium sulphate regime was assessed by control of convulsions with low dose protocol and by noting the total dose of magnesium sulphate required for control of convulsions. All cases were monitored for any sign of magnesium toxicity in the form of absent deep tendon reflexes, depression of respiration, decreased urine output and measurement of serum magnesium levels.

If any of the toxic effects was observed, next dose of magnesium sulphate was withheld, and the toxicity was managed by calcium gluconate. Time and mode of termination of pregnancy was decided as per patient profile. Baby was managed by pediatrician following vaginal delivery or cesarean section till discharge. Relevant information in every case was recorded in study Performa. The structured Performa consisted of patient's name, demographic profile, weight of women, obstetric history, period of gestation ,type of eclampsia, number of fits, convulsion: admission interval, blood pressure monitoring, serum magnesium level, mode of delivery, recurrence of fits, maternal and perinatal outcome.

\section{RESULTS}

The prospective study was done over a period of 1 year. Incidence of eclampsia in our hospital was 3.5\%. Patients presenting with eclampsia were most commonly belonging to younger age group i.e. less than 20 years of age (Table 1) followed by older age groups.

Table 1: Incidence of age in eclampsia.

\begin{tabular}{|l|l|l|}
\hline Age group & No. of cases & Percentage \\
\hline < 20 years & 50 & 50 \\
\hline 20-30 years & 42 & 42 \\
\hline >30 years & 8 & 8 \\
\hline
\end{tabular}

Women more than 30 years contributed $8 \%$ of the total population. Our hospital caters population from lower socioeconomic strata where couples get married at an early age.

This was the reason of higher incidence of teenagers in eclamptic women apart from usual high incidence in extremes of ages. $74 \%$ of women had no antenatal checkup whereas $26 \%$ had irregular antenatal visits. Most of the women belonged to lower socioeconomic status (Table 2).

Table 2: Socio-economic status of patients.

\begin{tabular}{|l|l|}
\hline Socio-economic status & Percent $(\mathbf{n}=\mathbf{1 0 0})$ \\
\hline Lower class & 80 \\
\hline Lower- middle & 18 \\
\hline Upper middle class & 2 \\
\hline Higher class & - \\
\hline
\end{tabular}

$80 \%$ of patients were primigravida who developed eclampsia (Table 3). Grand multipara were noted as the least incidence group. It is seen in most of the literatures that primigravida is associated with increased incidence of eclampsia.

Table 3: Parity distribution.

\begin{tabular}{|l|l|}
\hline Parity & Percent $(\mathbf{n = 1 0 0})$ \\
\hline 0 & 80 \\
\hline 1 & 13 \\
\hline 2 & 4 \\
\hline 3 or more & 3 \\
\hline
\end{tabular}


First time exposure to chorionic villi may be the reason of raised blood pressure and development of eclampsia. Patients presented at 37-40 weeks of period of gestation was the most common group of ante-partum eclampsia followed by post-partum eclampsia and then 34-37 weeks of period of gestation (Table 4).

Table 4: Incidence according to period of gestation.

\begin{tabular}{|l|l|}
\hline Period of gestation & Percentage \\
\hline$<34$ weeks & 3 \\
\hline $34-37$ weeks & 15 \\
\hline$>37$ weeks & 67 \\
\hline Postpartum & 15 \\
\hline
\end{tabular}

Intra-partum eclampsia had the least incidence (Table 5). $85 \%$ of the patients had blood pressure more than $160 / 110 \mathrm{mmHg}$.

Table 5: Types of eclampsia.

\begin{tabular}{|l|l|}
\hline Types of eclampsia & Percentage $(\mathbf{n = 1 0 0})$ \\
\hline Antepartum eclampsia & 77 \\
\hline Intrapartum eclampsia & 8 \\
\hline Postpartum eclampsia & 15 \\
\hline
\end{tabular}

After 24 hours of starting low dose magnesium sulphate, $60 \%$ had blood pressure equal to or less than $90 \mathrm{~mm}$ of $\mathrm{Hg}$ (Table 6) with or without the use of antihypertensive drugs. 39\% of eclamptic women had 3-6 fits, followed by $25 \%$ of women presented with more than 6 fits.

Table 6: Blood pressure distribution.

\begin{tabular}{|l|l|}
\hline Systolic blood pressure & Percentage \\
\hline $140-159 \mathrm{mmHg}$ & 4 \\
\hline $160-200 \mathrm{mmHg}$ & 67 \\
\hline >200mmHg & 29 \\
\hline Diastolic B.P. & \\
\hline $90-109 \mathrm{mmHg}$ & 20 \\
\hline $110-120 \mathrm{mmHg}$ & 54 \\
\hline$>120 \mathrm{mmHg}$ & 26 \\
\hline
\end{tabular}

On admission, $87 \%$ of women admitted with eclampsia had altered consciousness (Table 7).

Table 7: Level of consciousness.

\begin{tabular}{|l|l|}
\hline Level of consciousness & Percentage \\
\hline Oriented & 13 \\
\hline Altered consciousness & 80 \\
\hline Coma & 7 \\
\hline
\end{tabular}

$13 \%$ of women were oriented and recovered from fits at the time of admission and $7 \%$ were comatose.

$58 \%$ had $2+$ or more proteinuria (Table 8) and rest had lesser grade of proteinuria with dipstick method.
Table 8: Distribution of proteinuria.

\begin{tabular}{|l|l|l|}
\hline Proteinuria & No. of cases & Percentage \\
\hline Trace & 5 & 5 \\
\hline $1+$ & 37 & 37 \\
\hline $2+$ & 50 & 50 \\
\hline $3+$ & 8 & 8 \\
\hline
\end{tabular}

At the time of admission, blood sample was taken out for serum magnesium level, and then at 4 hours and 10 hours. $77 \%$ of case had serum magnesium level in the range of $1-1.5 \mathrm{meq} / \mathrm{dl}$ (Table 9 ) and $23 \%$ of women were in the range of $1.5-2 \mathrm{meq} / \mathrm{dl}$.

Table 9: Distribution pattern of serum magnesium level at admission.

\begin{tabular}{|l|l|l|}
\hline Serum $\mathrm{Mg}$ & No. of cases & Percentage \\
\hline $1-1.5 \mathrm{meq} / \mathrm{dl}$ & 77 & 77 \\
\hline $1.5-2 \mathrm{meq} / \mathrm{dl}$ & 23 & 23 \\
\hline
\end{tabular}

At 4 hours, 94\% of women had therapeutic range on starting low dose magnesium sulphate i.e. between $\mathrm{n}$ 4$7 \mathrm{meq} / \mathrm{dl}$ (Table 10) and $6 \%$ women were below the therapeutic level. At 10 hours, $95 \%$ of eclamptic women had therapeutic range (Table 11) and rest were below the target range. None had crossed the range of $7 \mathrm{meq} / \mathrm{dl}$.

Table 10: Serum Mg level at 4 hours of magnesium sulphate.

\begin{tabular}{|l|l|l|}
\hline Serum Mg & No. of cases & Percentage \\
\hline$<4 \mathrm{meq} / \mathrm{dl}$ & 6 & 6 \\
\hline $4-7 \mathrm{meq} / \mathrm{dl}$ & 94 & 94 \\
\hline$>7 \mathrm{meq} / \mathrm{dl}$ & 0 & 0 \\
\hline
\end{tabular}

Table 11: Serum Mg level at 10 hours of magnesium sulphate.

\begin{tabular}{|l|l|l|}
\hline Serum Mg & No. of cases & Percentage \\
\hline$<4 \mathrm{meq} / \mathrm{dl}$ & 5 & 5 \\
\hline $4-7 \mathrm{meq} / \mathrm{dl}$ & 95 & 95 \\
\hline$>7 \mathrm{meq} / \mathrm{dl}$ & 0 & 0 \\
\hline
\end{tabular}

In case of recurrence of fits, additional one dose of 2 gram of magnesium sulphate was given to 6 patients.

Table 12: Percentage of patients taking additional dose of magnesium sulphate.

\begin{tabular}{|l|l|}
\hline Additional dose & Percentage $(\mathrm{n}=\mathbf{1 0 0})$ \\
\hline 1 & 6 \\
\hline 2 & 1 \\
\hline
\end{tabular}

In one patient, another 2 doses of 2 grams of magnesium sulphate was given to control fits for recurrence. So, the recurrence of fits was only $7 \%$ of cases in eclamptic women treated with low dose magnesium sulphate (table 12). 
Table 13: Mode of delivery.

\begin{tabular}{|l|l|l|}
\hline Mode of delivery & No. of cases & Percentage $(\mathbf{n}=\mathbf{8 2})$ \\
\hline Vaginal & 43 & 52.44 \\
\hline Forceps & 12 & 14.6 \\
\hline Caesarean & 27 & 32.9 \\
\hline
\end{tabular}

Not even single patient shows any signs of toxicity after magnesium sulphate administration. Patients who had antepartum eclampsia, termination of pregnancy was done in view of maternal safety whereas intrapartum groups were already in labour. $52.44 \%$ were delivered vaginally and $14.6 \%$ were delivered instrumentally either with forceps or ventouse. $32.9 \%$ patients underwent caesarean section in view of unfavourable cervix i.e. maternal cause or fetal cause (Table 13).

\section{Table 14: Maternal outcome.}

\section{Maternal outcome}

Total no. of death

Deep coma with cardiorespiratory arrest

Pulmonary oedema 5 3 2

Among 100 cases of eclampsia, maternal death occurred in 5 cases which were mainly due to deep coma with cardio-respiratory arrest and pulmonary oedema (table 14). In eclamptic women, perinatal mortality was $24.4 \%$ who were given low dose magnesium sulphate and delivered in hospital.

\section{DISCUSSION}

The incidence of eclampsia in present study was $3.5 \%$ or 1 in 29 births. Eclampsia complicates 1 in 2000 pregnancies in Europe (6) to 1 in 3250 pregnancies in the US while in the developing countries, incidence of eclampsia is reported as 1 in 100 to 1 in 1700 pregnancies. ${ }^{7-10}$ The incidence in present study is higher than that of other developed countries, most of the developing countries as well as the incidence reported in other parts of India. This higher incidence is due to ignorance, poverty, and lack of awareness for health and inadequate or nil antenatal visits.

Early antenatal registration and regular antenatal visits play an important role in good pregnancy outcome. Regular antenatal checkups monitor blood pressure, proteinuria, pedal edema or any imminent signs of eclampsia. In the present study, it was observed that seventy four percent of the eclampsia cases were unbooked or unregistered and $26 \%$ had irregular antenatal checkups. Helmin in 1952 told that eclampsia will be found rare with effective antenatal care. Mudaliar and Menon and Dawn reported that $75 \%$ of eclampsia cases were primigravida. In the present study, authors found that $80 \%$ belonged to primigravida group. ${ }^{11-13}$

In the present study, authors observed that the majority of cases belonged to rural area and were from lower socio- economic group, with body mass lower than women from higher socio-economic group.

Majority of women had body weight less than 50 kilograms at the time of admission. Time tested Pritchard regime was mainly standardized for western women, having total body mass index much higher than women from developing countries including India. In the present study with low dose regime, authors observed that the eclamptic convulsions were controlled in 93\% cases. Sardesai Suman et al, in her large study on use of low dose Magnesium Sulphate reported that eclamptic convulsions were controlled in $90 \%$ cases. Rashida Begum et al in their study reported that eclamptic convulsions were controlled in $98 \%$ cases with Dhaka regime of magnesium sulphate. ${ }^{14}$ Results of present study are comparable with above mentioned studies regarding efficacy of low dose or modified dose regime for control of convulsions in eclampsia cases. There was 5\% maternal mortality in the present study. Maternal mortality reported by Sardesai Suman in her low dose regime was $2.63 \%$, whereas the maternal mortality reported by collaborative eclampsia trial with Pritchard regime was $3.8 \%$ and $5.2 \%$. Overall perinatal mortality in the present study was $24.4 \%$. Majority $(80 \%)$ of deaths were stillbirths and $20 \%$ were neonatal deaths. Prematurity, placental abruption and growth restriction were common causes for perinatal deaths. Sardesai Suman et al reported $33.90 \%$ perinatal mortality in their study.

There is no consistent evidence of inhibitory role of magnesium sulphate on myometrial contractility with the regimen used by Pritchard et al. In Pritchard's series, $67 \%$ of patients were delivered through vaginal route. Lucas et al. compared labour and delivery outcome in 480 nulliparous women treated with phenytoin for eclampsia with the outcome in 425 similar women treated with magnesium sulphate. The study showed that magnesium sulphate did not significantly alter the route of delivery. In present study, 53\%women had spontaneous vaginal delivery, while $14 \%$ had instrumental delivery. $33 \%$ of women were delivered by caesarean section. It shows that magnesium sulphate does not hamper uterine contractility and vaginal delivery is possible.

Kidney excretes magnesium sulphate from the body and toxicity can be avoided by ensuring adequate urine output i.e. at least $30 \mathrm{~mL} /$ hour. Fits are almost always prevented after achieving therapeutic level of serum magnesium of $4-7 \mathrm{mEq} / \mathrm{L}$. At $10 \mathrm{mEq} / \mathrm{L}$ patellar reflex is lost which is followed by respiratory depression on higher levels. Therefore, low dose regimens can be used safely and widely in all women of thin built. Moreover, low dose MgSO 4 can be used in cases with mild renal impairment which is usually present in these patients. Recent studies revealed supportive evidence about the neuro-protective effect of $\mathrm{MgSO}_{4}{ }^{15}$ Therefore, antenatal use of $\mathrm{MgSO}_{4}$ might increase with broader indications. In this respect, 
better understanding the dose and toxicity profile is important.

\section{CONCLUSION}

Prophylactic dose of magnesium sulphate in cases of imminent signs and symptoms of eclampsia and use of antihypertensive can prevent eclampsia. Efficacy of magnesium sulphate in prevention and treatment of eclamptic convulsions is time tested and supported with a variety of studies. However, protocols and dose of magnesium sulphate are not evidence based and narrow therapeutic index and toxicity is still a major concern in clinical use. Use of low dose regime is beneficial to patients as less amount of magnesium sulphate is to be given to patients making it cost -effective. Incidence of toxicity can be lowered down and maternal and perinatal outcome also gets improved.

Funding: No funding sources Conflict of interest: None declared

Ethical approval: The study was approved by the Institutional Ethics Committee

\section{REFERENCES}

1. The Eclampsia Trial Collaborative Group. Which anticonvulsant for women with eclampsia? Evidence from the Collaborative Eclampsia Trial. Lancet. 1995;345(8963):1455-63.

2. Cunningham, F Gary, Williams: Williams Obstetrics, Williams obstetrics / editors, F. Gary Cunningham, Kenneth J. Leveno, Steven L. Bloom, Jodi S. Dashe, Barbara L. Hoffman, Brian M. Casey, Catherine Y. Spong 22nd International edition. New York: McGraw-Hill. 2005; pp440-60.

3. Pritchard JA. The use of the magnesium ion in the management of eclamptogenic toxemias. Surgery, Gynecology Obstetrics. 1955;100(2):131-40.

4. Flowers CE, Easterling WE, White FD, Jung JM, Fox JT. Magnesium sulfate in toxemia of pregnancy: new dosage schedule based on body weight. Obstet Gynecol. 1962;19(3):315-27.

5. Sardesai Suman, Maira Shivanjali, Patil Ajit et al. Low dose magnesium sulphate therapy for eclampsia and imminent eclampsia- Regime tailored for Indian women. J. Obstet Gynecol India 2003;53(6):546-50.

6. Sardesai S. Low dose magnesium sulphate therapy for eclampsia and imminent eclampsia- Regime tailored for Indian women. J. Obstet Gynecol India. 2003;3:546-50.

7. Douglas KA, Redman CW. Eclampsia in the United Kingdom BMJ. 1994;309(6966):1395-400.

8. Ventura SJ, Martin JA, Curtin SC, Matthews TJ, Park MM. Births: final data for 1998. Hyattsville, MD: National Center for Health Statistics; 2000.

9. World Health Organisation International. Collaborative Study of Hypertensive Disorders of pregnancy. Geographic Variation in the incidence of hypertension in pregnancy. Am J Obstet Gynecol. 1958:158(1):80-3.

10. Crowther CA. Eclampsia at Harare Maternity Hospital. An epidemiological study. South African Med J Suid-Afrikaanse Tydskrif Vir Geneeskunde. 1985;68(13):927-9.

11. Bergström S, Povey G, Songane F, Ching CH. Seasonal incidence of eclampsia and its relationship to meteorological data in Mozambique. J Perinat Med. 1992;20(2):153-8.

12. Helmin R H J. Prevention of eclampsia and preeclampsia. Lancet. 1952;1:64.

13. Bangal V, Kwatra A, Raghav S, Jadhav S. Low dose magnesium sulphate regime for Eclampsia. Pravara Med Rev. 2009;4(3):13-5.

14. Toxaemia of pregnancy. ln: Dawn CS, Textbook of Obstetrics .Eighth ed. Calcutta. Dawn books, 1982:pp 172-202.

15. Begum R, Begum A, Johanson R, Ali MN, Akhter S. A low dose ('Dhaka') magnesium sulphate regime for eclampsia: Clinical findings and serum magnesium levels. Acta obstetricia et gynecologica Scandinavica. 2001;80(11):998-1002.

16. Costantine MM, Weiner SJ. Effects of antenatal exposure to magnesium sulfate on neuroprotection and mortality in preterm infants: a meta-analysis. Obstet Gynecol. 2009;114(2 Pt 1):354-64.

Cite this article as: Sinha K, Sinha SK. Role of low dose Magnesium sulphate in eclampsia. Int J Reprod Contracept Obstet Gynecol 2019;8:729-33. 